\title{
Activation of NR2A-Containing NMDA Receptors Is Not Obligatory for NMDA Receptor-Dependent Long-Term Potentiation
}

\author{
Carl Weitlauf, ${ }^{1 \star}$ Yumiko Honse, ${ }^{4 *}$ Yves P. Auberson, ${ }^{5}$ Masayoshi Mishina, ${ }^{6}$ David M. Lovinger, ${ }^{4}$ and \\ Danny G. Winder ${ }^{1,2,3}$ \\ ${ }^{1}$ Center for Molecular Neuroscience, ${ }^{2}$ Department of Molecular Physiology and Biophysics, and ${ }^{3}$. F. Kennedy Center for Research on Human \\ Development, Vanderbilt University School of Medicine, Nashville, Tennessee 37232-0615, ${ }^{4}$ Laboratory for Integrative Neuroscience, National Institute on \\ Alcohol Abuse and Alcoholism, National Institutes of Health, Rockville, Maryland 20852, ${ }^{5}$ Novartis Laboratories, CH-4002 Basel, Switzerland, and \\ 6University of Tokyo, Tokyo 113-0033, Japan
}

Activation of NMDA receptors (NMDARs) within the CNS represents a major signal for persistent alterations in glutamatergic signaling, such as long-term potentiation (LTP) and long-term depression. NMDARs are composed of a combination of NR1 and NR2 subunits, with distinct NR2 subunits imparting distinct characteristics on the receptor. One particular NR2 subunit, NR2A (NR $\epsilon 1$ ), has been proposed to play an integral role in LTP induction in the hippocampus and cortex. Here, we report studies investigating the role of NR2A in LTP induction in the dorsolateral bed nucleus of the stria terminalis (dlBNST). The putative NR2A-specific inhibitor NVP-AAM077 (AAM077) has been used previously to demonstrate the dependence of cortical and hippocampal LTP on NMDARs containing NR2A subunits. We report here the same sensitivity of LTP to pretreatment with AAM077 $(0.4 \mu \mathrm{M})$ in the dlBNST. However, inconsistent with the conclusion that LTP in the dlBNST is NR2A dependent, we see intact LTP in the dlBNST of NR2A knock-out mice. Because we also see blockade of this dlBNST LTP in NR2A knock-out mice after pretreatment with AAM077, we conclude that the antagonist is targeting non-NR2A subunitcontaining receptors. Using a variety of cultured cell types, we find that AAM077 $(0.4 \mu \mathrm{M})$ can attenuate transmission of NR2B subunitcontaining NMDARs when preapplied rather than coapplied with an agonist. Therefore, we conclude that NR2A is not obligatory for the induction of LTP in the dIBNST. Furthermore, our data demonstrate that care must be exercised in the interpretation of data generated with AAM077 when the compound is applied before an agonist.

Key words: glutamate; synaptic transmission; synaptic plasticity; NMDA receptor; ion channels; long-term potentiation

\section{Introduction}

We reported previously that NMDA receptor (NMDAR)dependent long-term potentiation (LTP) can be induced through high-frequency stimulation in the dorsolateral portion of the bed nucleus of the stria terminalis (dlBNST), a region thought to be important in stress/anxiety regulation of reward/ addiction-related behaviors (Weitlauf et al., 2004). Recent evidence suggests that NMDAR-dependent LTP is specifically dependent on NMDARs containing the NR2A (NR $\epsilon 1$ ) subunit. Although a deficiency in LTP has been reported in the hippocampus of NR2A knock-out mice (Sakimura et al., 1995), the primary evidence for the subunit specificity of LTP has been the sensitivity of hippocampal and cortical LTP to inhibition by an NR2A-

Received June 10, 2005; revised July 29, 2005; accepted July 29, 2005.

This work was supported by National Institute on Alcohol Abuse and Alcoholism (NIAAA) Grants AA08986 and AA013641 (D.G.W.) and by the Intramural Research Program of the National Institutes of Health-NIAAA.

${ }^{*}$ C.W. and Y.H. contributed equally to this work.

Correspondence should be addressed to Dr. Danny G. Winder, Department of Molecular Physiology and Biophysics, Room 724B, Roscoe Robinson Building, Vanderbilt University School of Medicine, 23rd and Pierce Avenue South, Nashville, TN 37232-0615. E-mail: danny.winder@vanderbilt.edu.

D01:10.1523/JNEUROSCI.2388-05.2005

Copyright $\odot 2005$ Society for Neuroscience $\quad$ 0270-6474/05/258386-05\$15.00/0 selective antagonist, NVP-AAM077 (AAM077; 0.1-0.5 $\mu \mathrm{M}$ ) (Liu et al., 2004; Mallon et al., 2004; Massey et al., 2004).

We report here that bath application of AAM077 $(0.4 \mu \mathrm{M})$ also attenuates NMDAR-dependent LTP in the dlBNST. However, inconsistent with the conclusion that this LTP is NR2A subunit dependent, we find that LTP in the dlBNST of NR2A knock-out mice is unchanged compared with wild-type littermates. This finding led us to more closely examine the specificity of AAM077 for NR2A subunit-containing NMDAR-mediated transmission in a variety of cell types. We report here that, much like other NR2-specific inhibitors, AAM077 produces time-dependent antagonism such that specificity for NR2A subunit-containing NMDARs is lost under conditions of prolonged exposure.

\section{Materials and Methods}

Field potential recordings. Male C57BL/6J or NR2A knock-out mice (6-8 weeks of age; The Jackson Laboratory, Bar Harbor, ME) were decapitated under isoflurane, and their brains were removed quickly and placed in ice-cold artificial CSF [ACSF; in mM: $124 \mathrm{NaCl}, 4.4 \mathrm{KCl}, 2.0 \mathrm{CaCl}_{2}, 1.2$ $\mathrm{MgSO}_{4}, 1 \mathrm{NaH}_{2} \mathrm{PO}_{4}, 10$ glucose, and $26 \mathrm{NaHCO}_{3}, \mathrm{pH}$ 7.2-7.4, 290-310 mOsm]. Hemisected coronal slices $(300 \mu \mathrm{m})$ were prepared with a Pelco (Redding, CA) vibratome.

Slices containing anterior portions of the dlBNST (bregma, 0.26-0.02 
mm) (Franklin and Paxinos, 1997) were selected using the internal capsule, anterior commissure, and stria terminalis as landmarks. After dissection, slices were transferred to an interface recording chamber in which they were perfused with heated $\left(\sim 29^{\circ} \mathrm{C}\right)$, oxygenated $(95 \%$ $\mathrm{O}_{2}-5 \% \mathrm{CO}_{2}$ ) ACSF at a rate of $\sim 2 \mathrm{ml} / \mathrm{min}$. Slices were allowed to equilibrate in ACSF for at least $1.5 \mathrm{~h}$ before experiments began. A bipolar stainless steel stimulating electrode and a borosilicate glass recording electrode filled with ACSF were placed in the dIBNST to elicit and record an extracellular field response. Baseline responses to a stimulus (50 $\mu \mathrm{s})$ at an intensity that produced $\sim 40 \%$ of the maximum response were recorded for at least $20 \mathrm{~min}$ at a rate of $0.05 \mathrm{~Hz}$. AAM077 (Novartis Laboratories, Basel, Switzerland) was bath applied where indicated. To elicit LTP, two trains of $100 \mathrm{~Hz}, 1 \mathrm{~s}$ tetanus were delivered with a $20 \mathrm{~s}$ intertrain interval at the same intensity as baseline test pulses.

Hippocampal neuron and human embryonic kidney cell culture and transfection. The culture protocol for hippocampal neurons was as described by Bekkers and Stevens (1991) and Chen and Lambert (2000), with minor modifications. A $35 \mathrm{~mm}$ culture dish was coated with $0.15 \%$ agarose (A-9918; Sigma, St. Louis, MO) and air dried. For microisland culture, a mixture of poly-D-lysine (P-6407; Sigma) at $0.4 \mathrm{mg} / \mathrm{ml}$ and collagen (354236; BD Biosciences, Bedford, MA) at $0.8 \mathrm{mg} / \mathrm{ml}$ was sprayed on the agarose-coated dish to make microdots. Culture dishes used for dispersed hippocampal primary cultures were not coated with agarose but instead were coated over their entire surface with $0.1 \mathrm{mg} / \mathrm{ml}$ poly-D-lysine. Neuronal cultures were prepared using the hippocampus taken from postnatal day 0 Sprague Dawley rats or NR2A knock-out mice. The hippocampus was dissected in minimum essential medium (MEM; 11090-081; Invitrogen, Grand Island, NY), collected, and dissociated with papain (PAP2; Worthington, Lakewood, NJ) at $\sim 35 \mathrm{U} / \mathrm{ml}$ for $30 \mathrm{~min}$ to $1 \mathrm{~h}$ at $37^{\circ} \mathrm{C}$. Small pieces of the hippocampus were triturated in culture medium (MEM supplemented with 2\% B-27; 17504-044; Invitrogen, Grand Island, NY), 0.1\% mito serum extender (355006; BD Biosciences), 5\% fetal bovine serum (FBS; 16000-044; Invitrogen, Grand Island, NY), 0.6\% dextrose (D-9434; Sigma), $1 \mathrm{~mm}$ sodium pyruvate (11360-070; Invitrogen, Grand Island, NY), and 0.5 mm glutamine with penicillin-streptomycin (10378-016; Invitrogen, Grand Island, NY) and centrifuged at $100 \times g$ for $5 \mathrm{~min}$. The pellets were resuspended in the culture medium and plated at a density of $\sim 50,000$ cells in a microdot 35 $\mathrm{mm}$ dish or at 250,000 cells in dispersed cultures. Cultures were maintained for $3-9 \mathrm{~d}$ in a $37^{\circ} \mathrm{C}$ humidified incubator with $5 \% \mathrm{CO}_{2}$.

Human embryonic kidney (HEK) 293 cells (CRL-1573; American Type Culture Collection, Manassas, VA) were grown in HEK cell culture medium (MEM Eagle, 30-2003; American Type Culture Collection) supplemented with $10 \%$ FBS. Cells were dissociated with trypsin-EDTA (25300-054; Invitrogen, Grand Island, NY) at $0.5 \mathrm{mg} / \mathrm{ml}$ and plated in a $35 \mathrm{~mm}$ dish at a density of $4 \times 10^{5}$ cells $/ \mathrm{ml}$. Cells were transfected with NR1-1a plus NRA or NR2B and green fluorescent protein cDNAs at a ratio of 2:3:1 (3 $\mu \mathrm{g}$ of total plasmid per dish) using a calcium phosphate transfection kit (K2780-01; Invitrogen, Carlsbad, CA). After transfection, $100 \mu \mathrm{M}$ ketamine (K-2735; Sigma) and $200 \mu \mathrm{M}$ D-1,2-amino-5phosphonopentanoic acid (APV; A-5282; Sigma) were added to the HEK culture medium, and cells were maintained in a $37^{\circ} \mathrm{C}$ humidified incubator at $5 \% \mathrm{CO}_{2}$. Whole-cell patch-clamp experiments were performed within $48-72 \mathrm{~h}$ after transfection.

Whole-cell patch-clamp recording. Whole-cell patch-clamp recording was performed at room temperature using a Multiclamp 700A (Molecular Devices, Union City, CA) amplifier. Culture dishes were superfused with external solution ( $150 \mathrm{~mm} \mathrm{NaCl}, 2.5 \mathrm{~mm} \mathrm{KCl}, 2.5 \mathrm{mM} \mathrm{CaCl}_{2}, 10 \mu \mathrm{M}$ glycine, $10 \mathrm{~mm}$ HEPES, and $10 \mathrm{~mm}$ dextrose, $\mathrm{pH}$ adjusted to 7.4 with $\mathrm{NaOH}$ and osmolarity adjusted to $\sim 335 \mathrm{mmol} / \mathrm{kg}$ with sucrose). To record NMDAR-mediated EPSCs, autaptic hippocampal neurons were voltage clamped at a holding potential of $-70 \mathrm{mV}$ and depolarized to $+10 \mathrm{mV}$ using a $1-2 \mathrm{~ms}$ pulse at $0.1 \mathrm{~Hz}$. AMPA receptor (AMPAR)mediated EPSCs were evoked by paired (interval of $50 \mathrm{~ms}$ ) $1 \mathrm{~ms}$ depolarization steps to $10 \mathrm{mV}$ at a rate of $0.1 \mathrm{~Hz}$. Before the evoked pulse, neurons were hyperpolarized to $-80 \mathrm{mV}$ for $10 \mathrm{~ms}$ to monitor changes in input and series resistances. Patch pipettes had a range of resistance from 1 to $3 \mathrm{M} \Omega$ when filled with an internal solution containing the following (in mM): $150 \mathrm{~K}$-gluconate, $1.4 \mathrm{CaCl}_{2}, 2 \mathrm{MgCl}_{2}, 10 \mathrm{EGTA}, 10 \mathrm{HEPES}, 3$
$\mathrm{Na}_{2} \mathrm{ATP}$, and $0.2 \mathrm{Na}_{2} \mathrm{GTP}$, $\mathrm{pH}$ adjusted to 7.35 with $\mathrm{KOH}$ and osmolarity adjusted to $\sim 325 \mathrm{mmol} / \mathrm{kg}$ with sucrose. The NMDAR antagonists AAM077 $(0.4 \mu \mathrm{M})$ and ifenprodil (3 $\mu \mathrm{M}, \mathrm{I}-2892$; Sigma) were applied to cells using a stepper motor-driven rapid solution exchange apparatus (Warner Fast-Step Perfusion system; Warner Instruments, Hamden, CT). In experiments examining autaptic synaptic currents, antagonists were applied continuously to the neuron beginning at least $15 \mathrm{~s}$ before evoking an EPSC, and antagonist application was maintained between EPSCs. NMDAR- or AMPAR-mediated currents were isolated by adding $5 \mu \mathrm{M}$ 2,3-dioxo-6-nitro-1,2,3,4-tetrahydrobenzo[f] quinoxaline-7-sulfonamide (0373; Tocris, Ellisville, MO) or $50 \mu \mathrm{M} \mathrm{APV}$, respectively, to the external solution.

To examine AAM077 and ifenprodil effects on NMDAR expressed in HEK 293 cells, transfected cells were voltage clamped at a holding potential of $-60 \mathrm{mV}$. After establishing the whole-cell mode, cells were lifted and series resistance (up to $10 \mathrm{M} \Omega$ ) was compensated by $80 \%$. The intracellular recording solution for HEK cell experiments contained (in mM) $140 \mathrm{CsCl}, 10$ EGTA, 2 ATP, and 10 HEPES. The intracellular solution $\mathrm{pH}$ was adjusted to 7.2 with $\mathrm{CsOH}$, and osmolarity was adjusted to $315 \mathrm{mmol} / \mathrm{kg}$ with sucrose. Solutions of $100 \mu \mathrm{M}$ NMDA and/or antagonists $(0.4 \mu \mathrm{M}$ AAM077 or $3 \mu \mathrm{M}$ ifenprodil) were applied to cells for $5 \mathrm{~s}$ using a stepper motor-driven solution exchange apparatus every minute. In the "simultaneous application protocol," antagonists were not present before the drug application and were only applied during the $5 \mathrm{~s}$ agonist applications. In contrast, in the "pretreatment protocol," antagonists were applied for at least $30 \mathrm{~s}$ before combined agonist and antagonist application. This protocol yields antagonist application periods similar to the application protocol used in experiments on autaptic hippocampal neurons. Signals were filtered using a Bessel filter at $2 \mathrm{kHz}$, and data were acquired at $5 \mathrm{kHz}$ with pClamp 8 software (Molecular Devices).

Data analysis. For LTP experiments, each point represents the peak response of the $\mathrm{N} 2$ averaged from three traces for each minute. This value was plotted as a percentage of the averaged response from a $20 \mathrm{~min}$ baseline phase preceding drug application and/or tetanus. The N1 was measured in a similar manner; experiments in which the N1 changed by $>20 \%$ were discarded. To measure for significant effects, responses over a 5 min time span were averaged for each experiment. These were compared with averaged responses from other time points within the experiment or at the same time point across experimental conditions using paired and independent Student's $t$ tests, respectively. A minimum criteria of $p<0.05$ was used to determine significance.

For experiments on HEK 293 and hippocampal dispersed culture cells, the percentage of control current amplitude during antagonist applications was calculated as the average amplitude for all responses during antagonist application over the mean of the current amplitudes obtained before and after antagonist treatment. To estimate antagonist effects on current just after the onset of agonist application, we made isochronal measurements of current amplitude at the time point when peak current was observed in the absence of antagonist. Steady-state current was measured at a time point just before the end of the $5 \mathrm{~s}$ agonist application. In a subset of experiments, full recovery from ifenprodil inhibition was not examined. In these experiments, the percentage of control was defined as current amplitude during ifenprodil application divided by values obtained before antagonist application. Inhibition by ifenprodil was of similar magnitude regardless of the method of measurement. In experiments on autapses, only inhibition of peak current amplitude was measured. This was accomplished by taking the ratio of the average EPSC amplitude in the presence of the antagonist to the averages of EPSCs evoked before and after antagonist application. The AMPAR-mediated paired-pulse ratio (PPR) was determined by calculating the ratio of the amplitude of the second EPSC peak to that of the first EPSC. The results were normalized to the values obtained before and after antagonist application.

\section{Results}

NMDAR-dependent LTP in the BNST persists in the absence of the NR2A subunit

In slices prepared from C57BL/6J mice, we induced LTP with two $100 \mathrm{~Hz}, 1 \mathrm{~s}$ trains with a $20 \mathrm{~s}$ intertrain interval. Potentiation was significant and lasted $>1 \mathrm{~h}$ (Fig. $1 \mathrm{~A}$, filled squares). We showed 

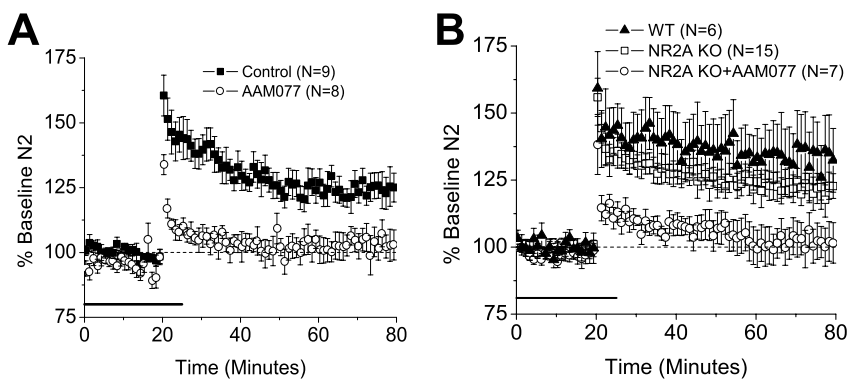

Figure 1. NMDAR-dependent LTP in the dIBNST does not require NR2A subunit-containing receptors. $A$, Averaged time course of synaptic field potentials after high-frequency stimulation $(21 \mathrm{~s}$ trains, $100 \mathrm{~Hz}$ ) in coronal slices containing the dIBNST from adult $\mathrm{C57BL} / 6 \mathrm{~J}$ mice. Pretreatment with AAM077 $(0.4 \mu \mathrm{M})$ for 30 min significantly attenuated LTP (open circles) compared with interleaved controls (filled squares) $(p<0.05) . \boldsymbol{B}$, LTP in the dIBNST was unaffected in NR2A knock-outs (open squares) compared with wild-type (WT) littermates (filled triangles) $(p=0.28)$. LTP in NR2A knock-outs was blocked by pretreatment with AAM077 ( $0.4 \mu \mathrm{M}$; open circles) $(p<0.05)$.

previously using the same tetanus protocol that this LTP is abolished by the NMDAR antagonist DL-AP-5 (Weitlauf et al., 2004). Similar to previous experiments (Liu et al., 2004; Mallon et al., 2004; Massey et al., 2004), bath application of AAM077 (0.4 $\mu \mathrm{M})$ for a period of $30 \mathrm{~min}$ attenuated this dIBNST LTP $(n=8 ; p<$ 0.05 compared with controls) (Fig. $1 A$, open circles). Based on these data, we predicted that LTP would be disrupted in the dlBNST of NR2A knock-out mice. We found, however, that dlBNST LTP in NR2A knock-out mice was unchanged compared with wild-type littermates $(n=15 ; p=0.28$ compared with wild-type littermates) (Fig. $1 B$, open squares). Moreover, we found that pretreatment with AAM077 (0.4 $\mu \mathrm{M})$ attenuated dlBNST LTP induction in NR2A knock-out mice in a manner similar to that observed in wild-type mice ( $n=7 ; p<0.05$ compared with knock-out controls) (Fig. $1 \mathrm{~B}$, open circles).

\section{Preapplication of AAM077 produces substantial inhibition of peak currents evoked by activation of NR2B-containing receptors}

Previous literature reported a 100 -fold higher specificity of AAM077 for NR2A relative to NR2B (Auberson et al., 2002; Liu et al., 2004). These measurements were taken when varying concentrations of the antagonist were coapplied with glutamate to modulate the induction of NMDAR-mediated currents in oocytes expressing human NR1-1a/NR2A or NR1-1a/NR2B cRNA. Based on these data, a concentration of $0.4 \mu \mathrm{M}$ should effectively inhibit NR2A-containing receptors while essentially sparing NR2B-containing receptors. It is important to note, however, that other NR2 subunit-specific antagonists display timedependent inhibition kinetics. In particular, the NR2B subunitspecific antagonist ifenprodil displays much greater inhibition of NR2B-containing NMDARs when it is applied before agonist application (Legendre and Westbrook, 1991; Tovar and Westbrook, 1999) (Fig. 2C). Because our LTP studies in brain slices require preapplication of the antagonist, we tested the idea that AAM077 may produce time-dependent inhibition of NR2Bcontaining subunits using HEK cells expressing recombinant receptors containing rat NR1a/NR2A or NR1-1a/NR2B subunits.

Similar to previous studies, we see attenuation of the steadystate (ss) current and, to a lesser degree, the peak (pk) current from NR1-1a/NR2A receptors in response to AAM077 $(0.4 \mu \mathrm{M})$ application (Fig. 2B) (Liu et al., 2004). However, the attenuation of each current was much more complete when the HEK cells

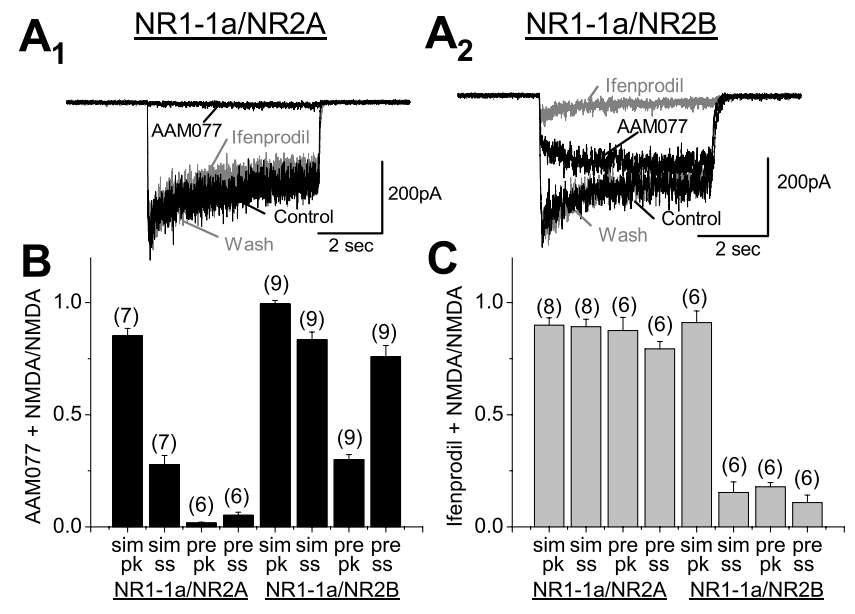

Figure 2. Attenuation of NMDA-induced currents by NR2-specific inhibitors in HEK cells expressing recombinant NMDARs. $\boldsymbol{A}$, Representative traces of NMDA-induced currents in HEK cells expressing NR1-1a/NR2A $\left(\boldsymbol{A}_{1}\right)$ and NR1-1a/NR2B $\left(\boldsymbol{A}_{2}\right)$ under control conditions, after preapplication of AAM077 $(0.4 \mu \mathrm{M})$, after preapplication of ifenprodil $(3 \mu \mathrm{M})$, and after washout. $\boldsymbol{B}$, Averaged amount of attenuation of NMDA-induced currents by AAM077 $(0.4 \mu \mathrm{m})$ in HEK cells expressing NR1-1a/NR2A (left) and NR1-1a/NR2B (right). C, Averaged amount of attenuation of NMDA-induced currents by ifenprodil ( $3 \mu \mathrm{m})$ in HEK cells expressing NR1-1a/NR2A (left) and NR1-1a/NR2B (right). Values are expressed as the ratio of the response in the presence of NMDA plus antagonist compared with the response in the presence of NMDA alone. The numbers of averaged cells are indicated in parentheses above the bars. sim, Simultaneous application of antagonist and NMDA; pre, preapplication of antagonist 30 s before NMDA; pk, peak current (measured at the time point at which control currents reach maximum amplitude); ss, steady-state current.

were pretreated with AAM077 30 s before application of NMDA (Fig. $2 A_{1}, B$, pre) compared with those that received simultaneous application of agonist and antagonist (Fig. $2 B$, sim). Consistent with previous reports, we see only negligible attenuation of NMDA-induced currents in cells expressing NR1-1a/NR2B receptors when AAM077 $(0.4 \mu \mathrm{M})$ is coapplied with the agonist (Fig. $2 B$, sim). However, we see significant attenuation of the pk current through these receptors under conditions of antagonist pretreatment (Fig. $2 A_{2}, B$, pre). To control for nonspecific drug application effects, we also measured the amount of attenuation seen in the presence of the NR2B subunit-specific antagonist ifenprodil. As predicted, ifenprodil $(3 \mu \mathrm{M})$, whether preapplied or coapplied, had a minimal effect on pk and ss currents in cells expressing NR2A-containing NMDARs (Fig. 2C, left). Significant attenuation of both pk and ss currents was only seen under conditions of preapplication in cells expressing NR2Bcontaining NMDARs (Fig. $2 A_{2}, C$, right).

\section{Preapplication of AAM077 dramatically reduces} NMDAR-mediated EPSCs in autaptic synapses from NR2A knock-out mice

To further verify that AAM077 loses its specificity for NR2Acontaining NMDARs under conditions of pretreatment, we repeated our experiments in cultured hippocampal neurons under two conditions that effectively removed NR2A subunitcontaining NMDARs. First, we used dispersed cultures of rat hippocampal neurons during a time at which NR2B subunitcontaining receptors are the predominant receptor subtype (3-4 $\mathrm{d}$ in vitro). This predominance of NR2B-containing receptors was verified by blocking $>75 \%$ of the ss and pk currents in these cells with preapplication of ifenprodil $(3 \mu \mathrm{M})$ (Fig. $3 A, C)$. Preapplication of AAM077 $(0.4 \mu \mathrm{M})$ also attenuated the pk current by $>75 \%$ (Fig. $3 A, B$ ). This treatment had little effect on the ss cur- 


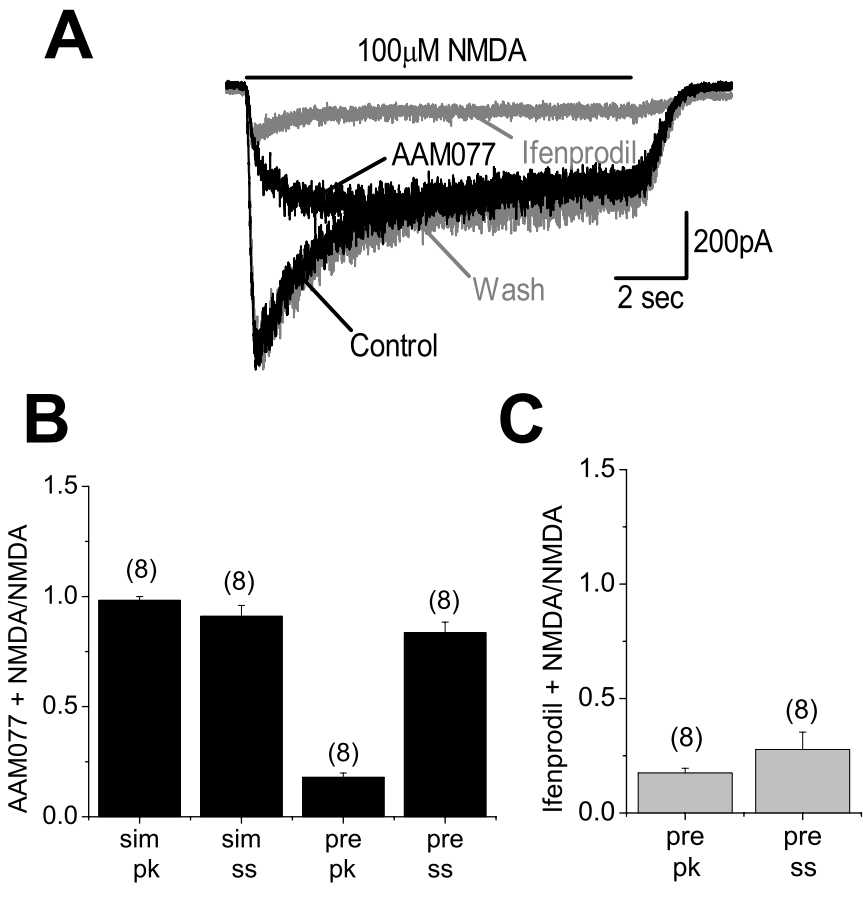

Figure 3. Attenuation of NMDA-mediated current by NR2-specific inhibitors in dispersed cultured hippocampal neurons (3-4 d in vitro). $\boldsymbol{A}$, Representative traces of NMDA-induced currents under control conditions, after preapplication of AAM077 $(0.4 \mu \mathrm{M})$, after preapplication of ifenprodil $(3 \mu \mathrm{M})$, and after washout. $\boldsymbol{B}$, Averaged amount of attenuation of NMDAinduced currents by AAM077 $(0.4 \mu \mathrm{M})$. C, Averaged amount of attenuation of NMDA-induced currents by ifenprodil $(3 \mu \mathrm{m})$. The numbers of averaged neurons are indicated in parentheses above the bars. Data were obtained from three separate culture dishes from two separate litters for each condition. sim, Simultaneous application of antagonist and NMDA; pre, preapplication of antagonist 30 s before NMDA; pk, peak current (measured at the time point at which control currents reach maximum amplitude); ss, steady-state current.

rent (Fig. $3 A, B)$. As before, simultaneous application of AAM077 $(0.4 \mu \mathrm{M})$ with NMDA had little effect on the pk and ss currents (Fig. 3B). Second, we used autaptic neuron cultures produced from the hippocampus of NR2A subunit protein knock-out mice. In these experiments, instead of directly applying agonist over a time frame of several seconds, activation of NMDARs was achieved by depolarization-evoked release of glutamate from presynaptic sites to produce a synaptic NMDAR-dependent EPSC. Like ifenprodil, pretreatment with AAM077 led to an $\sim 70 \%$ reduction of these synaptically evoked NMDAR-mediated EPSCs (Fig. 4A, B, left).

To test for nonspecific effects on glutamatergic transmission, we also measured the effect of ifenprodil and AAM077 on AMPAR-mediated synaptic transmission in the autaptic neuron cultures from the hippocampus of NR2A knock-out mice. To isolate AMPAR-mediated currents, we stimulated the neurons in the presence of APV $(50 \mu \mathrm{M})$. Under these conditions, we see no significant effect on these currents when pretreated with either ifenprodil $(3 \mu \mathrm{M})$ or AAM077 $(0.4 \mu \mathrm{M})$ (Fig. $4 C, D)$. Furthermore, we see no change in PPR after pretreatment with either inhibitor, suggesting that neither drug affects the release probability of glutamate (Fig. 4D).

\section{Discussion}

In total, our data support two main conclusions. First, at the antagonist concentrations used here as well as in previous studies (0.1-0.5 $\mu \mathrm{M}$ ) (Liu et al., 2004; Mallon et al., 2004; Massey et al., 2004), the high degree of specificity of AAM077 for NR2A- over
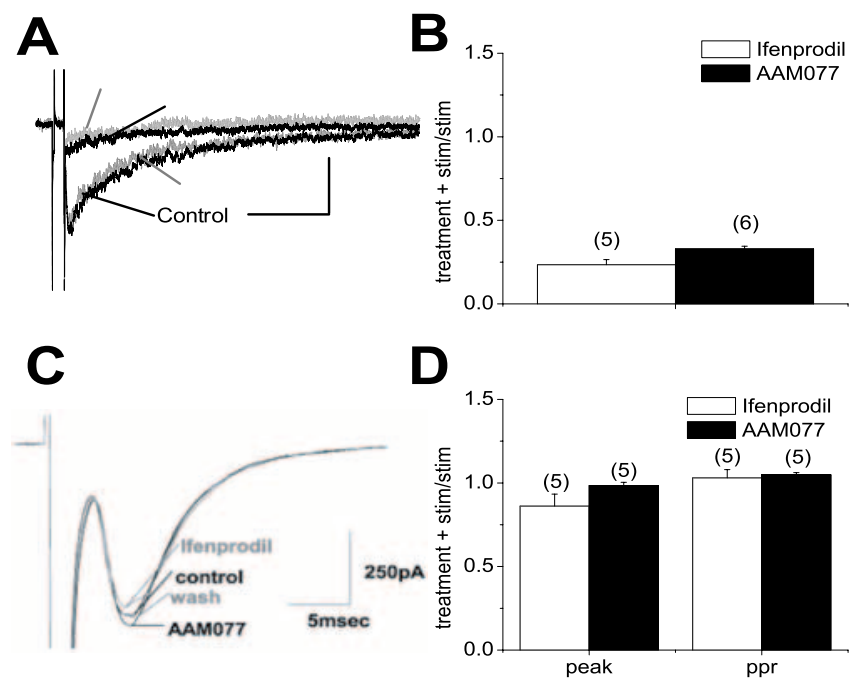

Figure 4. Attenuation of NMDAR-mediated, but not AMPAR-mediated, transmission by NR2-specific inhibitors in autaptic cell cultures from the hippocampus of NR2A knock-out mice. $\boldsymbol{A}$, Representative traces of synaptically evoked NMDAR-mediated EPSCs under control conditions in the presence of AAM077 $(0.4 \mu \mathrm{M})$, in the presence of ifenprodil ( $3 \mu \mathrm{M})$, and after washout. $\boldsymbol{B}$, Averaged amount of attenuation of synaptically evoked NMDAR-mediated EPSCS by ifenprodil ( $3 \mu \mathrm{m}$; gray bar) and AAM077 (0.4 $\mu \mathrm{m}$; black bar). C, Representative traces of synaptically evoked AMPA-mediated EPSCs under control conditions, in the presence of AAM077 $(0.4 \mu \mathrm{M})$, in the presence of ifenprodil $(3 \mu \mathrm{M})$, and after washout. D, Averaged amount of attenuation of synaptically evoked AMPA-mediated EPSCs (peak) and paired-pulse ratios (ppr) by AAM077 (0.4 $\mu \mathrm{m}$; closed bars) and ifenprodil ( $3 \mu \mathrm{m}$; open bars). The numbers of averaged neurons are indicated in parentheses above the bars. Data were obtained from a single culture for each condition.

NR2B-containing NMDARs only occurs under conditions of coapplication of agonist and antagonist, or perhaps preapplication of agonist. When the antagonist is preapplied (as it is in most brain slice experiments such as our LTP studies), selectivity is reduced. This, taken with the observations that AAM077 also has a high affinity for NR2C subunit-containing receptors (Feng et al., 2004; Y. P. Auberson, personal communication) compromises the interpretation of results with this compound. The effect of AAM077 on NMDA-induced currents from NR2B-containing receptors obtained in HEK cells and dispersed hippocampal cultures was primarily on the peak rather than the steady-state portion of the current. This peak current is thought to be in some ways analogous to synaptically induced NMDAR-mediated EPSCs. Consistent with this, we saw marked attenuation of synaptically evoked currents from NR2B-containing receptors obtained in autaptic neurons prepared from NR2A knock-out mice.

Second, our results indicate that NR2A is not obligatory for NMDAR-dependent LTP in all regions of the CNS. We found that LTP in the BNST in slices prepared from adult NR2A knockout mice was indistinguishable from that observed in wild-type mice. Although it is possible that developmental compensation may occur in the NR2A knock-out mice, NMDAR LTP in area CA1 is disrupted in this line (Sakimura et al., 1995). Furthermore, evidence suggests that the loss of NR2A is not compensated by maintenance of NR2B-containing subunits in the synapse during development (Townsend et al., 2003). Our data are consistent with a number of other studies indicating a lack of general requirement for the NR2A subunit in NMDAR-dependent LTP. For example, although LTP is disrupted in area CA1 in adult mouse slices prepared from NR2A knock-out mice, LTP in these knock-outs is intact in slices prepared from 2- to 3-week-old mice 
(Ito et al., 1996). Furthermore, NR2B-specific antagonists reduce LTP induced by pairing protocols in the visual cortex (Yoshimura et al., 2003) (but see Massey et al., 2004). Finally, transgenic overexpression of NR2B resulted in enhancement of LTP in area CA1 (Tang et al., 1999).

\section{References}

Auberson YP, Allgeier H, Bischoff S, Lingenhoehl K, Moretti R, Schmutz M (2002) 5-Phosphonomethylquinoxalinediones as competitive NMDA receptor antagonists with a preference for the human $1 \mathrm{~A} / 2 \mathrm{~A}$, rather than 1A/2B receptor composition. Bioorg Med Chem Lett 12:1099-1102.

Bekkers JM, Stevens CF (1991) Excitatory and inhibitory autaptic currents in isolated hippocampal neurons maintained in cell culture. Proc Natl Acad Sci USA 88:7834-7838.

Chen H, Lambert NA (2000) Endogenous regulators of G protein signaling proteins regulate presynaptic inhibition at rat hippocampal synapses. Proc Natl Acad Sci USA 97:12810-12815.

Feng B, Tse HW, Skifter DA, Morley R, Jane DE, Monaghan DT (2004) Structure-activity analysis of a novel NR2C/NR2D-preferring NMDA receptor antagonist: 1-(phenanthrene-2-carbonyl) piperazine-2,3dicarboxylic acid. Br J Pharmacol 141:508-516.

Franklin KBJ, Paxinos G (1997) The mouse brain in stereotaxic coordinates. San Diego: Academic.

Ito I, Sakimura K, Mishina M, Sugiyama H (1996) Age-dependent reduction of hippocampal LTP in mice lacking $N$-methyl-D-aspartate receptor epsilon 1 subunit. Neurosci Lett 203:69-71.

Legendre P, Westbrook GL (1991) Ifenprodil blocks $N$-methyl-D-aspartate receptors by a two-component mechanism. Mol Pharmacol 40:289-298.

Liu L, Wong TP, Pozza MF, Lingenhoehl K, Wang Y, Sheng M, Auberson YP,
Wang YT (2004) Role of NMDA receptor subtypes in governing the direction of hippocampal synaptic plasticity. Science 304:1021-1024.

Mallon AP, Auberson YP, Stone TW (2005) Selective subunit antagonists suggest an inhibitory relationship between NR2B and NR2A-subunit containing $N$-methyl-D-aspartate receptors in hippocampal slices. Exp Brain Res 162:374-383.

Massey PV, Johnson BE, Moult PR, Auberson YP, Brown MW, Molnar E, Collingridge GL, Bashir ZI (2004) Differential roles of NR2A- and NR2B-containing NMDA receptors in cortical long-term potentiation and long-term depression. J Neurosci 24:7821-7828.

Sakimura K, Kutsuwada T, Ito I, Manabe T, Takayama C, Kushiya E, Yagi T, Aizawa S, Inoue Y, Sugiyama H, Mishina M (1995) Reduced hippocampal LTP and spatial learning in mice lacking NMDA receptor epsilon 1 subunit. Nature 373:151-155.

Tang YP, Shimizu E, Dube GR, Rampon C, Kerchner GA, Zhuo M, Liu G, Tsien JZ (1999) Genetic enhancement of learning and memory in mice. Nature 401:63-69.

Tovar KR, Westbrook GL (1999) The incorporation of NMDA receptors with a distinct subunit composition at nascent hippocampal synapses in vitro. J Neurosci 19:4180-4188.

Townsend M, Yoshii A, Mishina M, Constantine-Paton M (2003) Developmental loss of miniature $\mathrm{N}$-methyl-D-aspartate receptor currents in NR2A knockout mice. Proc Natl Acad Sci USA 100:1340-1345.

Weitlauf C, Egli RE, Grueter BA, Winder DG (2004) High-frequency stimulation induces ethanol-sensitive long-term potentiation at glutamatergic synapses in the dorsolateral bed nucleus of the stria terminalis. J Neurosci 24:5741-5747.

Yoshimura Y, Ohmura T, Komatsu Y (2003) Two forms of synaptic plasticity with distinct dependence on age, experience, and NMDA receptor subtype in rat visual cortex. J Neurosci 23:6557-6566. 